\title{
Recension av Rainer Nyberg, Skriv vetenskapliga uppsatser och avhandlingar med stöd av IT och Internet (Vasa Edutime 1999)
}

\section{Av Börje Björkman}

\author{
Länk till presentation av Börje Björkman
}

IT:s företräden har länge framhållits som fantastiska. Med hjälp av datorerna, och idag även med Internet, skall man kunna göra i stort sett vad som helst. Och onekligen har väldigt mycket förenklats och förbättrats sedan skrivmaskinens glansdagar: idag är det möjligt för en författare eller forskare att på ett annat sätt än tidigare behålla kontrollen över sin arbetsprocess, från idé- och litteratursökande, skrivande och formgivning till distribution och försäljning. Till medaljens baksida hör - naturligtvis - att det krävs väldigt mycket av den skribent som verkligen vill utnyttja IT:s alla möjligheter.

Icke desto mindre har vi åtminstone i Sverige länge saknat en utförlig vägledning på svenska, som både tar upp konkreta problem och som kan hjälpa en mer eller mindre oerfaren författare fram mot en lyckad uppsats-, avhandlings- eller annan forskningsrapportsprodukt. Föreliggande bok, Skriv vetenskapliga uppsatser och avhandlingar med stöd av IT och Internet, skriven av den finländske pedagogikprofessorn Rainer Nyberg, verksam vid Åbo Akademis pedagogiska fakultet i Vasa tycker jag dock kan rekommenderas till de flesta unga akademiker. Rainer Nyberg tillhör de ännu så länge ganska fåtaliga akademiker som på allvar tagit till sig detta nya medium och som försökt sätta sina tankar om hur man konkret bör och faktiskt kan utnyttja dagens IT-teknik på pränt. Vad vi fått med denna bok är, grovt uttryckt, en sorts guidebok i forskningsrapportsskrivandets ädla konst.

Helt 'ny' är visserligen inte denna bok. Detta är den tredje och omarbetade upplagan som kommit på relativt kort tid - de båda första såldes ganska snart slut vilket också det skvallrar om att ämnet är angeläget och viktigt. Förutom att flera saker tillkommit i och med denna upplaga och att innehållet 'uppdaterats' ytterligare - väldigt mycket händer ju inom IT-området och därtill väldigt snabbt - bör för en svensk läsekrets särskilt nämnas två saker. Ett: att den tidigare så 'finländska' texten anpassats till svenska förhållanden. Vi får alltså reda på en hel del om vad som förväntas av en student eller forskare inom respektive akademiska utbildningstradition. Skrifter med liknande syften finns visserligen redan, också i Sverige, men knappast av denna omfattning varför Rainer Nybergs bok känns ytterligt välkommen även här.

Och två: att boken helt i takt med tiden och ämnet också har en egen webbplats http://www.vasa.abo.fi/pf/li/itped/skrivet/ - där det fortsättningsvis för var en går att hålla sig 'uppdaterad' hela tiden. Om man i denna service också inkluderar ytterligare ett par speciellt framtagna webbplatser om forskningsinformation respektive forskningsmetoder adresserna finns i en av bokens bilagor - så har man både som nybörjare och mer erfaren forskare här fătt en god grund att stå på.

Skriv vetenskapliga uppsatser... är därför en mycket användbar och nyttig bok, för såväl den förhållandevis erfarne som den blivande forskaren/författaren. I femton kapitel går författaren igenom hela forsknings- och skrivprocessen steg för steg, från val av ämne och handledningsproblematik, över problemformuleringar, metodfrågor och informationssökning till sammanställning, layout och publicering. Hela tiden är det väl strukturerat, resonemanget är ofta uppbyggt med utgångspunkt från en fråga. Skriv- och 
forskningsprocessen gås på ett pedagogiskt sätt igenom från början till slut. Möjligen kan jag ibland tycka att det är lite väl utförligt, till och med lite omständligt ibland. Det verkar som om författaren har försökt täcka in så många områden och

utbildnings/examinationsnivåer som möjligt, svara på så många verkliga och tänkbara frågor som möjligt. Jag tänker exempelvis på avsnitten "Hur många böcker skall man läsa" och "Hur många respondenter måste jag ha?" [för att utföra en empirisk undersökning med hjälp av intervjuer]. Frågorna är naturligtvis viktiga och de ställs säkert av studenterna. Men lika fullt är de omöjliga att svara på och detta gör i sin tur att de svar eller, kanske snarare riktlinjer Rainer Nyberg ger inte alltid säger så mycket. Det blir ibland ett alltför generellt resonemang.

Kanske är det också detta som gör att jag ibland har lite svårt att se vilken målgrupp som Rainer Nyberg främst riktar sig till. Kanske hade det varit bättre om man försökt dela på den information som kan behövas för olika utbildningar/nivåer. Å andra sidan kan man ju säga att de delar som behövs för att lyckas i olika forskningssammanhang och på olika utbildningsnivåer till stor del är desamma, och att det därför är en poäng att faktiskt ha resonemangen på ett och samma ställe. Jag vet inte. Kanske beror mina funderingar på att jag kommit så långt i min egen forskningsproduktionsprocess - ett avhandlingsarbete - och därtill inom ett forskningsområde - humaniora/historia - som inte behandlas så utförligt i boken.

Nå dessa anmärkningar är ganska perifera och förtar knappast det i övrigt mycket positiva helhetsintryck jag fått av denna bok. Skriv vetenskapliga uppsatser och avhandlingar med stöd av IT och Internet är, som redan nämnts, en välkommen och behövlig bok som kan användas på flera olika sätt. Med sin vinkling mot dagens teknikutveckling fyller denna praktiska handbok fullt klart ett tomrum som alltför länge lämnats obearbetat.

(C) Börje Björkman 